\title{
The St Jude Medical Trifecta aortic pericardial valve: Results from a global, multicenter, prospective clinical study
}

\author{
Joseph E. Bavaria, MD, ${ }^{\mathrm{a}}$ Nimesh D. Desai, MD, PhD, ${ }^{\mathrm{a}}$ Anson Cheung, MD, ${ }^{\mathrm{b}}$ Michael R. Petracek, MD, \\ Mark A. Groh, MD, ${ }^{d}$ Michael A. Borger, MD, ${ }^{e}$ and Hartzell V. Schaff, MD $^{f}$
}

Background: The St Jude Medical Inc (St Paul, Minn) Trifecta valve is a novel aortic biological prosthesis that incorporates several design features, including a true supra-annular sewing cuff, a stent design that maximizes valve hemodynamics while minimizing leaflet stresses, and an ethanol-based anticalcification technology. This study establishes the safety and early clinical and hemodynamic performance of the Trifecta valve.

\begin{abstract}
Methods: The Trifecta bioprosthesis was implanted in 1014 eligible patients between 2007 and 2009 at 31 centers. The mean age of the population was $72.5 \pm 9.0$ years, of whom $650(64.1 \%)$ were male and $364(35.9 \%)$ were female. Eighty-two subjects $(8.1 \%)$ had undergone previous open surgery. Indications for aortic valve replacement surgery included stenosis in 556 patients (54.8\%), regurgitation in 61 patients $(6.0 \%)$, and mixed pathology in 397 patients $(39.2 \%)$.
\end{abstract}

Results: The overall follow-up included 844.3 late patient-years. Early ( $\leq 30$ day) mortality occurred in 18 patients $(1.8 \%$ ), and there were 23 late ( $\geq 31$ days) deaths yielding a linearized mortality rate of $2.72 \%$ per late patient-year. There were 27 early thromboembolic events, including $8(0.8 \%)$ strokes, $17(1.7 \%)$ reversible neurologic events, and $2(0.2 \%)$ systemic embolic events. There were no instances of early valve thrombosis, endocarditis, or clinically significant hemolysis. There were 16 late thromboembolic events (linearized rate of $1.90 \%$ per year of follow-up), including 4 strokes and 12 reversible neurologic events. In total, there were 5 late valve explants, including 1 structural deterioration and 4 prosthetic valve endocarditis cases. Overall, freedom from valve explant was $99.4 \%$ at 2 years. At the time of discharge, average mean gradients ranged from 9.3 to $4.1 \mathrm{~mm} \mathrm{Hg}$ and effective orifice area ranged from 1.58 to $2.50 \mathrm{~cm}^{2}$ for valve sizes 19 to $29 \mathrm{~mm}$, respectively.

Conclusions: The St Jude Medical Trifecta valve is a unique pericardial bioprosthesis with design elements that provide excellent hemodynamic performance while providing ease of implantation. Long-term follow-up continues to confirm the promising results of this innovative bioprosthesis. (J Thorac Cardiovasc Surg 2014;147:590-7)

Bioprosthetic valves are implanted in approximately $80 \%$ of patients requiring aortic valve replacement in North America. ${ }^{1}$ During the past 4 decades, there has been a consistent, iterative improvement in bioprosthetic valve longevity and hemodynamic performance based on valve design and tissue processing. ${ }^{2-5}$ The St Jude Medical Inc (St Paul, Minn) Trifecta valve is a novel biological prosthesis that incorporates several design features, including a true supra-annular sewing cuff, a stent design

\footnotetext{
From the Division of Cardiovascular Surgery, ${ }^{\mathrm{a}}$ Hospital of the University of Pennsylvania, Philadelphia, Pa; Division of Cardiovascular Surgery, ${ }^{\mathrm{b}}$ St Paul's Hospital, Vancouver, British Columbia, Canada; Department of Cardiac Surgery, ${ }^{\mathrm{c}}$ Vanderbilt Medical Center, Nashville, Tenn; Mission Health and Hospitals, ${ }^{\mathrm{d}}$ Asheville, NC; Department of Cardiac Surgery, ${ }^{\mathrm{e}}$ Herzzentrum Leipzig GmbH, Leipzig, Germany; and Division of Cardiovascular Surgery, ${ }^{\mathrm{f}}$ Mayo Clinic, Rochester, Minn.

Disclosures: Authors have nothing to disclose with regard to commercial support.

Received for publication Aug 1, 2012; revisions received Dec 1, 2012; accepted for publication Dec 20, 2012; available ahead of print March 13, 2013.

Address for reprints: Joseph E. Bavaria, MD, Hospital of the University of Pennsylvania, 3400 Spruce St, Philadelphia, PA 19104 (E-mail: joseph.bavaria@uphs. upenn.edu).

0022-5223/\$36.00

Copyright (C) 2014 by The American Association for Thoracic Surgery

http://dx.doi.org/10.1016/j.jtcvs.2012.12.087
}

that maximizes valve hemodynamics while minimizing leaflet stresses, and an ethanol-based anticalcification technology.

The Trifecta pericardial aortic valve was evaluated in a rigorous multicenter US Food and Drug Administration Investigational Device Exemption study conducted between 2007 and 2011. Data from 31 centers in the United States, Canada, Germany, France, Italy, The Netherlands, and Switzerland involving 1022 patients were collected to obtain regulatory approvals. This study establishes the safety and early clinical and hemodynamic performance of the Trifecta valve in one of the largest prospective evaluations ever performed on any surgical aortic valve prosthesis.

\section{MATERIALS AND METHODS Patients}

The Trifecta bioprosthesis was implanted in 1022 patients between 2007 and 2009. Eight subjects were excluded from the analysis who did not meet the prespecified study eligibility criteria, resulting in an analysis dataset of 1014 patients. A list of participating institutions and Principal Investigators is in Appendix Table I. Inclusion criteria necessitated a patient of legal age requiring aortic valve replacement who could sign for informed consent and complete the follow-up requirements of the study. Exclusion criteria included being pregnant or nursing; requiring other concomitant valve 


\section{Abbreviations and Acronyms \\ EOA = effective orifice area \\ EOAI $=$ effective orifice area index \\ NYHA $=$ New York Heart Association \\ PPM = patient-prosthesis mismatch \\ TAVR $=$ transcatheter aortic valve replacement}

replacement surgery; active endocarditis; presence of other significant cardiovascular abnormality, such as aortic dissection; acute preoperative (within 30 days before implant) neurologic event; renal dialysis; a history of substance abuse in the past year; inability to perform follow-up requirements or predicted life expectancy less than 2 years; or participating in another Investigational Device Exemption or Investigational New Drug study. Institutional review board approval was obtained at every participating site.

The mean age of the population was $72.5 \pm 9.0$ years. Among the 1014 study patients, $95(9.4 \%)$ were aged less than 60 years at the time of implant and $210(20.7 \%)$ were aged 80 years or more at the time of implant (Figure 1). There were 650 men $(64.1 \%)$ and 364 women (35.9\%). Eightytwo subjects $(8.1 \%)$ had undergone previous open surgery. Preoperatively, the majority of patients had New York Heart Association (NYHA) class II or III symptoms. NYHA class IV symptoms occurred preoperatively in 55 patients $(5.4 \%)$. Indications for aortic valve replacement surgery included stenosis in 556 patients $(54.8 \%)$, regurgitation in 61 patients $(6.0 \%)$, and mixed pathology in 397 patients $(39.2 \%)$. Sixteen patients $(1.6 \%)$ had a previous prosthetic aortic valve or aortic homograft explanted, whereas the remainder of procedures were performed on the patient's native aortic valve. Calcific stenosis of a trileaflet valve was observed in 696 patients (68.6\%), bicuspid pathology was observed in 295 patients $(29.1 \%)$, and 23 patients $(2.3 \%)$ had rheumatic disease. Other aortic valve disease and causes were observed in 53 patients $(5.2 \%)$. Preoperative demographic information is presented in Table 1.

\section{Aortic Valve Implantation Operative Details}

Valve description. The Trifecta valve is a 3-leaflet stented pericardial valve designed for supra-annular placement in the aortic position. The valve is fabricated using a polyester-covered titanium stent. The stent, excluding the sewing cuff, is covered with porcine pericardial tissue. This covering is designed to provide protection from mechanical wear by allowing only tissue-to-tissue contact during valve opening and closing. A silicone insert in the polyester sewing cuff is contoured to conform to the shape of the native annulus while providing access to the coronary artery ostia. The valve leaflets are fabricated from bovine pericardium. The porcine and bovine pericardium are preserved and crosslinked in glutaraldehyde. Glutaraldehyde, formaldehyde, and ethanol are used in the valvesterilization process. The Trifecta valve is processed with ethanol-based Linx anticalcification technology. ${ }^{6}$ Valve sizes are available in 2-mm increments from 19 to $29 \mathrm{~mm}$. The nominal valve size is based on the outer diameter of the stent. Implanted sizes are outlined in Figure 2. The valve is designed to be implanted in the true supra-annular position, typically with noneverting pledgeted mattress sutures placed on the ventricular side of the aortic annulus.

Among 1014 implanted valves, 56 were placed with simple interrupted sutures, 34 were placed with nonpledgeted mattress sutures, 57 were placed using a continuous running technique, 56 were placed using an intraannular technique with everting pledgeted mattress sutures placed on the aortic side, and 811 were placed using the recommended supra-annular technique. Concomitant procedures included coronary artery bypass grafting in 372 patients $(36.7 \%)$, mitral valve repair in 38 patients $(3.7 \%)$, tricuspid valve repair in 23 patients $(2.3 \%)$, Maze or other cardiac ablation

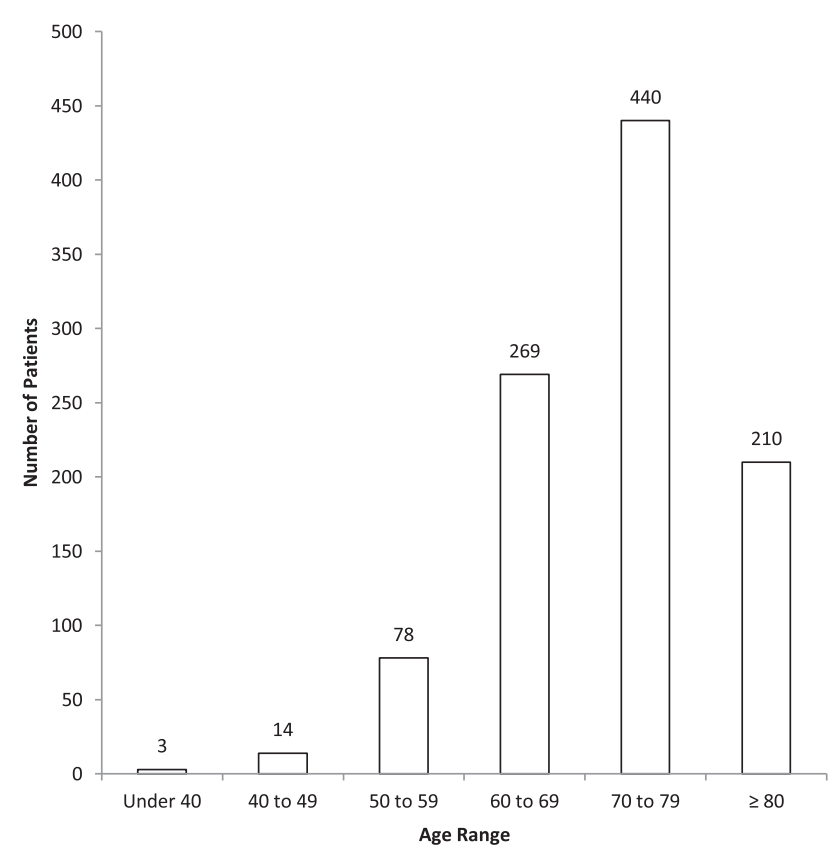

FIGURE 1. Distribution of enrolled patients by age range, $\mathrm{N}=1014$.

procedures in 66 patients $(6.5 \%)$, and atrial septal defect repairs in 38 patients $(3.7 \%)$. Aortic root enlargement was performed in 17 patients $(1.7 \%)$. An intra-aortic balloon pump was placed at the time of surgery in 17 patients $(1.7 \%)$. The mean aortic crossclamp time for isolated aortic valve replacement with the Trifecta valve was $64.3 \pm 25.5$ minutes. Operative information is presented in Table 2.

End point definitions. Adverse events were classified according to the standardized definitions from the Society of Thoracic Surgeons/ American Association for Thoracic Surgery "Guidelines for Reporting Morbidity and Mortality and Cardiac Valvular Operations" and the requirements of the US Food and Drug Administration. ${ }^{7}$ Events were classified as occurring early (within 30 days of implant) or late ( $\geq 31$ days after implant).

\section{Data Analysis}

Statistical analyses were performed using SAS software (v 9; SAS institute Inc, Cary, NC). Descriptive data are presented as mean values with standard deviation for continuous variables and as counts with percentages for categoric variables. Statistical significance was determined using a 2-sample $t$ test or Fisher exact test as appropriate. Late adverse event rates (ie, those occurring $\geq 31$ days postimplant) were determined using both linearized rates and Kaplan-Meier analyses.

\section{Patient Follow-up}

The overall late follow-up included 844.3 patient-years with a median follow-up interval of 0.90 years (standard deviation, 0.45 years; interquartile range, $0.50-0.99$ years). The completeness of follow-up at 1 and 2 years was $97.7 \%$ and $98.0 \%$ of patients, respectively. Echocardiographic evaluation was completed at discharge, 6 months, and 1 year in $98.4 \%, 96.9 \%$, and $94.5 \%$ of patients, respectively. The follow-up was performed at the local investigating sites by clinic evaluation at 6 months, 1 year, and annually thereafter. Study visits included clinical determination of NYHA functional classification, study echocardiograms, blood assessment including plasma free hemoglobin, medication review including anticoagulants, and documentation of any adverse events. Study echocardiograms and blood laboratory assessments were evaluated at central core laboratories. 
TABLE 1. Patient demographics

\begin{tabular}{|c|c|}
\hline Variable & All implants $(\mathrm{N}=1014)$ \\
\hline Age at implant $(\mathrm{y})$ & $72.5 \pm 9.0(32-95)$ \\
\hline Subject gender (male) & $64.1 \%(650)$ \\
\hline \multicolumn{2}{|l|}{ Medical history } \\
\hline Hypertension & $81.9 \%(830)$ \\
\hline Low ejection fraction $(<50 \%)$ & $12.4 \%(126)$ \\
\hline Hyperlipidemia & $71.2 \%(722)$ \\
\hline Coronary artery disease & $58.2 \%(590)$ \\
\hline Smoking history (previous or current) & $55.7 \%(565)$ \\
\hline Diabetes & $24.8 \%(251)$ \\
\hline Carotid artery disease & $21.3 \%(216)$ \\
\hline Pulmonary hypertension & $17.3 \%(175)$ \\
\hline Myocardial infarction & $12.9 \%(131)$ \\
\hline Peripheral vascular disease & $10.9 \%(111)$ \\
\hline Kidney disease & $7.0 \%(71)$ \\
\hline $\begin{array}{l}\text { Stroke, cerebrovascular accident, } \\
\text { reversible ischemic neurologic deficit }\end{array}$ & $6.0 \%(61)$ \\
\hline Transient ischemic attack & $7.3 \%(74)$ \\
\hline \multicolumn{2}{|l|}{ Preoperative NYHA } \\
\hline Class I & $6.6 \%(67)$ \\
\hline Class II & $44.1 \%(447)$ \\
\hline Class III & $43.9 \%(445)$ \\
\hline Class IV & $5.4 \%(55)$ \\
\hline \multicolumn{2}{|l|}{ Predominant preoperative cardiac rhythm } \\
\hline Sinus & $88.3 \%(895)$ \\
\hline Atrial fibrillation/flutter & $8.8 \%(89)$ \\
\hline Paced & $2.7 \%(27)$ \\
\hline Other & $0.3 \%(3)$ \\
\hline \multicolumn{2}{|l|}{ Previous cardiovascular surgery/procedure } \\
\hline None & $72.4 \%(734)$ \\
\hline Aortic valve repair & $0.3 \%(3)$ \\
\hline Aortic valve replacement & $1.5 \%(15)$ \\
\hline Mitral valve repair & $0.1 \%(1)$ \\
\hline Mitral valve replacement & $0.0 \%(0)$ \\
\hline CABG & $6.5 \%(66)$ \\
\hline Percutaneous coronary intervention & $14.3 \%(145)$ \\
\hline Balloon valvuloplasty & $1.1 \%(11)$ \\
\hline
\end{tabular}

\section{RESULTS \\ Clinical Events}

Early ( $\leq 30$ days postimplant) mortality occurred in 18 patients $(1.8 \%)$. There were 27 early thromboembolic events, including $8(0.8 \%)$ strokes, $17(1.7 \%)$ reversible neurologic events, and $2(0.2 \%)$ systemic embolic events. Of the 27 early thromboembolic events, 8 were known to be in atrial fibrillation. There were $81(8.0 \%)$ instances of major bleeding, of which $61(6.0 \%)$ were procedurerelated. There was 1 early valve explant due to suture injury to a congenitally malpositioned intramural coronary artery. The bioprosthetic valve was functioning normally at the time of explant. The coronary artery was not obstructed by the prosthesis. There were no instances of early structural deterioration, valve thrombosis, endocarditis, or clinically significant hemolysis. Early clinical events are presented in Table 3.

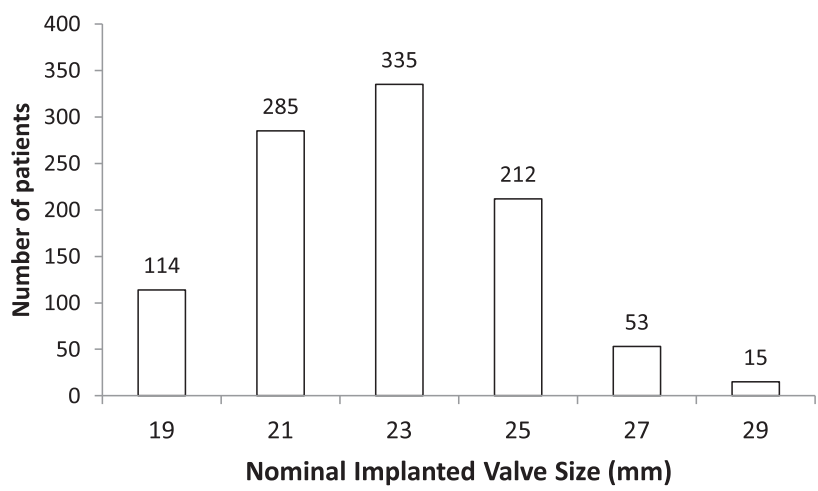

FIGURE 2. Distribution of valves sizes implanted, $\mathrm{N}=1014$.

\section{Late Clinical Events}

Late clinical events are those events that occurred 31 days or more postimplant. There were 23 deaths, yielding a linearized mortality rate of $2.72 \%$ per late patient-year. Of these, 3 $(0.36 \%$ per late patient-year) were valve related and $4(0.47 \%$ per late patient-year) were cardiac related. Overall KaplanMeier survival was $95.8 \%$ at 1 year and $94.5 \%$ at 2 years. Freedom from valve-related mortality was $99.4 \%$ at 2 years.

There were 16 thromboembolic events (linearized rate of $1.90 \%$ per late patient-year of follow-up), including 4 strokes and 12 reversible neurologic events. Of these patients, 1 was known to be in atrial fibrillation. Overall freedom from thromboembolic events was $92.9 \%$ at 2 years. There were 22 instances of major bleeding (linearized rate of $2.61 \%$ per late patient-year). Freedom from major bleeding events was $86.0 \%$ at 2 years. There was 1

TABLE 2. Operative details

\begin{tabular}{lcr}
\hline \multicolumn{1}{c}{ Variable } & $\begin{array}{c}\text { No. of patients } \\
(\mathbf{N}=\mathbf{1 0 1 4})\end{array}$ & Mean \pm SD (min) \\
\hline Aortic crossclamp time & & \\
All subjects & 1014 & $83.2 \pm 37.3$ \\
With concomitant procedure & 586 & $96.9 \pm 38.5$ \\
Without concomitant procedure & 428 & $64.3 \pm 25.5$ \\
Cardiopulmonary bypass time & & \\
All subjects & 1014 & $111.5 \pm 51.0$ \\
With concomitant procedure & 586 & $129.7 \pm 52.8$ \\
Without concomitant procedure & 428 & $86.6 \pm 35.8$ \\
\hline & No. of patients \\
& $(\mathbf{N}=\mathbf{1 0 1 4})$ & \\
\hline Concomitant procedures & 372 & \\
CABG & 38 & 36.7 \\
Mitral valve repair & 23 & 3.7 \\
Tricuspid valve repair & 42 & 2.3 \\
Maze & 29 & 4.1 \\
Cardiac ablation & 66 & 2.9 \\
Maze or cardiac ablation & 38 & 6.5 \\
ASD & 17 & 3.7 \\
Root enlargement & 1.7 \\
\hline SD, Standard deviation; $C A B G$, coronary artery bypass grafting; $A S D$, atrial septal defect.
\end{tabular}


TABLE 3. Early adverse event rates

\begin{tabular}{|c|c|c|}
\hline $\begin{array}{c}\text { Safety measures for the early } \\
\text { postoperative period }\end{array}$ & $\begin{array}{c}\begin{array}{c}\text { No. of early } \\
\text { events* }\end{array} \\
\mathrm{N}=1014\end{array}$ & $\begin{array}{c}\text { Early rate } \dagger \\
\%(95 \% \\
\text { upper CL) }\end{array}$ \\
\hline Thromboembolism & 27 & $2.7(3.7)$ \\
\hline Neurologic & 25 & $2.5(3.4)$ \\
\hline Transient ischemic attack & 3 & $0.3(0.8)$ \\
\hline Reversible ischemic neurologic deficit & 14 & $1.4(2.2)$ \\
\hline Stroke & 8 & $0.8(1.4)$ \\
\hline Systemic & 2 & $0.2(0.6)$ \\
\hline Valve thrombosis & 0 & $0.0(0.3)$ \\
\hline Major bleed & 81 & $8.0(9.5)$ \\
\hline Procedure related & 61 & $6.0(7.4)$ \\
\hline Anticoagulant or antiplatelet related & 14 & $1.4(2.2)$ \\
\hline $\begin{array}{l}\text { Anticoagulant with or without } \\
\text { antiplatelet }\end{array}$ & 9 & $0.9(1.5)$ \\
\hline Other bleed & 6 & $0.6(1.2)$ \\
\hline Nonstructural dysfunction & 3 & $0.3(0.8)$ \\
\hline Paravalvular leak & 1 & $0.1(0.5)$ \\
\hline Minor paravalvular leak & 1 & $0.1(0.5)$ \\
\hline Major paravalvular leak & 0 & $0.0(0.3)$ \\
\hline Endocarditis & 0 & $0.0(0.3)$ \\
\hline Clinically significant hemolysis & 0 & $0.0(0.3)$ \\
\hline Structural deterioration & 0 & $0.0(0.3)$ \\
\hline Reoperation & 1 & $0.1(0.5)$ \\
\hline Repair & 0 & $0.0(0.3)$ \\
\hline Explant & 1 & $0.1(0.5)$ \\
\hline Mortality & 18 & $1.8(2.6)$ \\
\hline Valve-related & 2 & $0.2(0.6)$ \\
\hline
\end{tabular}

plant. †Early rate is calculated as number of early events*100/number of subjects.

instance of nonstructural dysfunction that did not require explantation. Endocarditis occurred in 9 patients (linearized rate of $1.07 \%$ per late patient-year). Freedom from prosthetic valve endocarditis was $98.6 \%$ at 2 years. There was 1 instance of structural valve deterioration requiring explantation. There was no overt calcification of the valve cusps. In total, there were 5 valve explants, including 1 case of structural deterioration and 4 cases of prosthetic valve endocarditis. Overall, freedom from valve explant was $99.4 \%$ at 2 years. There were no instances of valve thrombosis or clinically significant hemolysis. Late clinical event rates are summarized in Table 4 and Figures 3 to 6.

\section{New York Heart Association Results}

At 2 years of clinical follow-up, $83.5 \%$ of patients had NYHA class I functional status. A further $14.4 \%$ of patients had NYHA class II status, and $2.1 \%$ of patients had NYHA class III status. There were no instances of NYHA functional class IV status in follow-up. At 2 years, freedom from NYHA class III or IV symptoms was $96.1 \%$.

\section{Hemodynamic Results}

Hemodynamic results at discharge and 1 year for each valve size are presented in Figures 7 to 10. At the time of
TABLE 4. Late adverse event rates

\begin{tabular}{|c|c|c|}
\hline $\begin{array}{c}\text { Safety measures for the } \\
\text { latepostoperative period } \\
(\geq \mathbf{3 1} \text { d postimplant })\end{array}$ & $\begin{array}{c}\text { No. of } \\
\text { late } \\
\text { events }\end{array}$ & $\begin{array}{c}\text { Late rate }^{*} \\
\text { (late patient-y }=\mathbf{8 4 4 . 3 )} \\
\% / \text { /late patient-y } \\
(95 \% \text { upper } \mathrm{CL}) \\
\end{array}$ \\
\hline Thromboembolism & 16 & $1.90(2.88)$ \\
\hline Neurologic & 16 & $1.90(2.88)$ \\
\hline Transient ischemic attack & 11 & $1.30(2.16)$ \\
\hline $\begin{array}{l}\text { Reversible ischemic neurologic } \\
\text { deficit }\end{array}$ & 1 & $0.12(0.56)$ \\
\hline Stroke & 4 & $0.47(1.08)$ \\
\hline Systemic & 0 & $0.00(0.35)$ \\
\hline Valve thrombosis & 0 & $0.00(0.35)$ \\
\hline Major bleed & 22 & $2.61(3.72)$ \\
\hline $\begin{array}{l}\text { Anticoagulant or antiplatelet } \\
\text { related }\end{array}$ & 16 & $1.90(2.88)$ \\
\hline $\begin{array}{l}\text { Anticoagulant with or without } \\
\text { antiplatelet }\end{array}$ & 7 & $0.83(1.56)$ \\
\hline Other bleed & 6 & $0.71(1.40)$ \\
\hline Nonstructural dysfunction & 1 & $0.12(0.56)$ \\
\hline Paravalvular leak & 0 & $0.00(0.35)$ \\
\hline Minor paravalvular leak & 0 & $0.00(0.35)$ \\
\hline Major paravalvular leak & 0 & $0.00(0.35)$ \\
\hline Endocarditis & 9 & $1.07(1.86)$ \\
\hline Clinically significant hemolysis & 0 & $0.00(0.35)$ \\
\hline Structural deterioration & 1 & $0.12(0.56)$ \\
\hline Reoperation & 5 & $0.59(1.25)$ \\
\hline Repair & 0 & $0.00(0.35)$ \\
\hline Explant & 5 & $0.59(1.25)$ \\
\hline Mortality & 23 & $2.72(3.86)$ \\
\hline Valve-related & 3 & $0.36(0.92)$ \\
\hline
\end{tabular}

$C L$, Confidence limit. *More than 31 -day adverse event rate (\%) is calculated as the number of events divided by the total patient-years times 100 .

discharge, average mean gradients ranged from 9.3 to 4.1 $\mathrm{mm} \mathrm{Hg}$ and average peak gradients ranged from 17.8 to $7.8 \mathrm{~mm} \mathrm{Hg}$ for valve sizes 19 to $29 \mathrm{~mm}$, respectively. At 1 year of follow-up, average mean gradients ranged from 10.7 to $4.7 \mathrm{~mm} \mathrm{Hg}$ and average peak gradients ranged from 19.9 to $9.2 \mathrm{~mm} \mathrm{Hg}$ for valve sizes 19 to $29 \mathrm{~mm}$, respectively. Average effective orifice area (EOA) ranged from

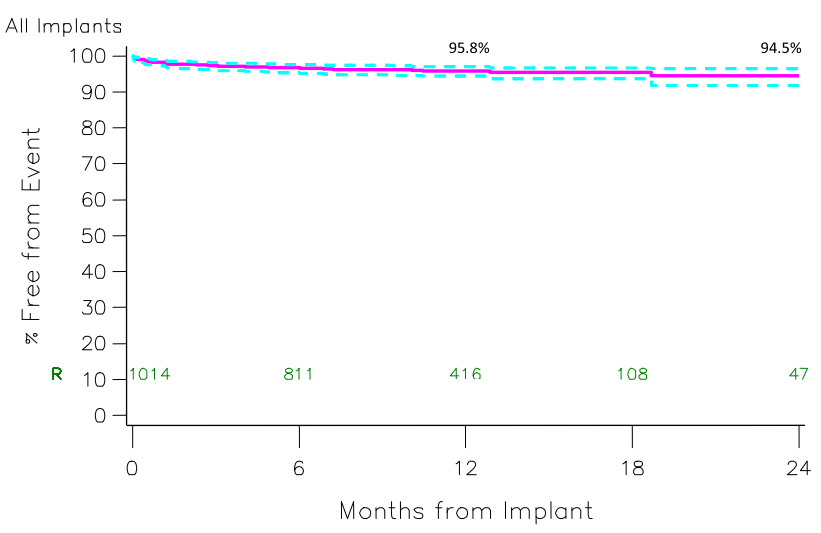

FIGURE 3. All-cause mortality. 


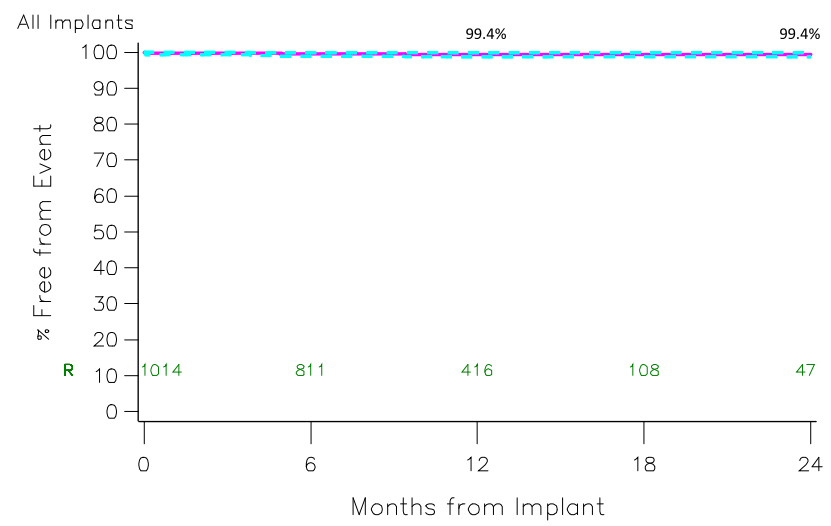

FIGURE 4. Valve-related mortality.

1.58 to $2.50 \mathrm{~cm}^{2}$ at the time of discharge and from 1.41 to $2.35 \mathrm{~cm}^{2}$ at 1 year for valve sizes 19 to $29 \mathrm{~mm}$, respectively.

At the time of discharge, 12 patients $(1.2 \%)$ had mild aortic insufficiency, and 4 patients $(0.4 \%)$ had moderate aortic insufficiency. There were no early cases of severe insufficiency. At 1 year, 11 patients $(1.8 \%)$ had mild aortic insufficiency, 6 patients $(1.0 \%)$ had moderate aortic insufficiency, and 3 patients $(0.5 \%)$ had severe aortic insufficiency (Figure 11). At 1 year, moderate or greater aortic insufficiency was observed in 9 patients $(1.5 \%)$. Paravalvular leaks were exceedingly uncommon with only 1 $(0.1 \%)$ minor paravalvular leak observed in the early period (Figure 12).

Mild to moderate patient-prosthesis mismatch (PPM) as defined by an effective orifice area index (EOAI) of 0.65 to $0.85 \mathrm{~cm}^{2} / \mathrm{m}^{2}$ occurred in 209 patients $(22.8 \%)$ at the time of discharge. Severe PPM, defined as an EOAI less than 0.65 $\mathrm{cm}^{2} / \mathrm{m}^{2}$, was found in 18 patients $(2.0 \%)$ at the time of discharge and 32 patients $(5.5 \%)$ at 1 year. Overall freedom from severe PPM at 1 year was $94.8 \%$. Mean indexed left ventricular mass for subjects who had values at all 3 postoperative time points decreased from $115.4 \mathrm{~g} / \mathrm{m}^{2}$ at the time of discharge to $107.0 \mathrm{~g} / \mathrm{m}^{2}$ at 6 months, $105.1 \mathrm{~g} / \mathrm{m}^{2}$ at 1 year,

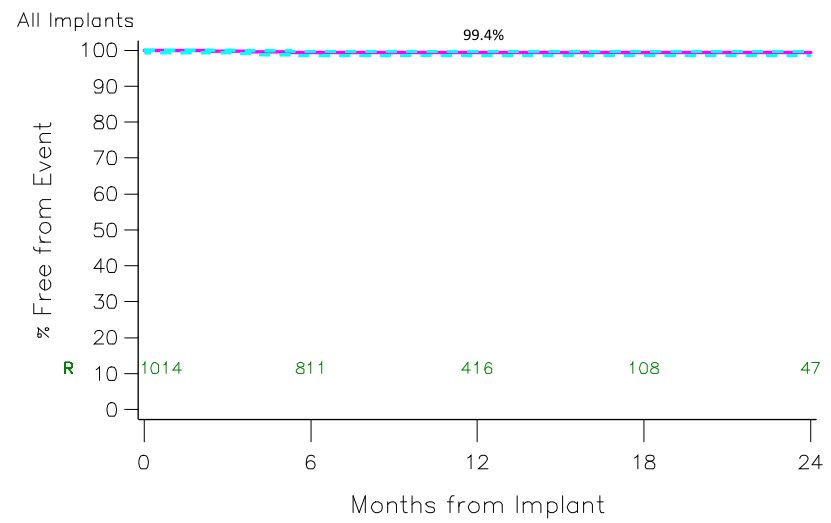

FIGURE 5. Freedom from Trifecta (St Jude Medical Inc, St Paul, Minn) valve explant.

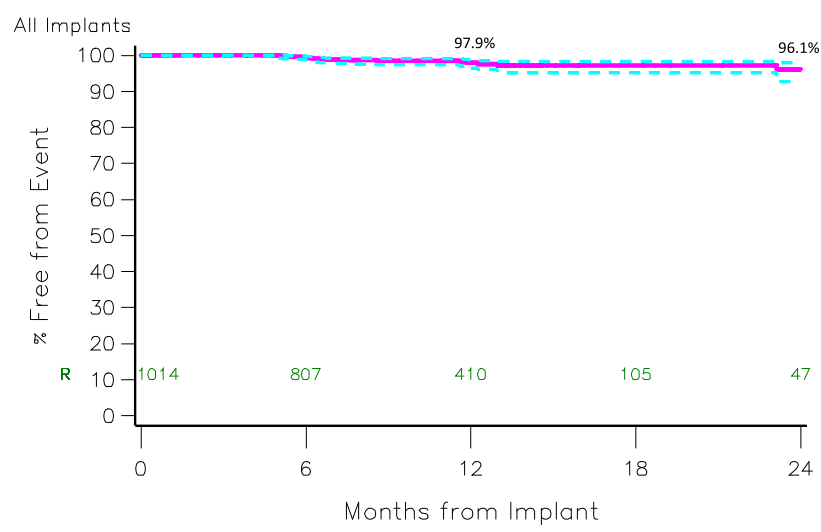

FIGURE 6. Freedom from NYHA III or greater. NYHA, New York Heart Association.

and $100.2 \mathrm{~g} / \mathrm{m}^{2}$ at 2 years $(P<.001$ for all time points vs left ventricular mass at discharge) (Figure 13).

\section{DISCUSSION}

Characteristics of the ideal aortic prosthesis include ease of implant, lack of intrinsic thrombogenicity that does not require therapeutic anticoagulation, no residual transvalvular pressure gradient, a physiologic orifice area that can adapt to exercise conditions, and long-term durability. ${ }^{6,8,9}$ The Trifecta valve prosthesis was designed to specifically address some of the fundamental limitations of previous aortic valve bioprostheses. Specifically, it was designed with a concave, slightly scalloped sewing ring to conform to the aortic annulus and provide adequate clearance for the native coronary arteries. Attachment of the bioengineered single sheet of bovine pericardium around the external aspects of the titanium stent allows for maximal cylindrical opening during systole. In addition, the titanium stent has intrinsic distensibility, potentially allowing for further expansion of the prosthesis in highload conditions such as exercise.

The purpose of the current investigation was to establish the safety and hemodynamic profile of the Trifecta aortic valve prosthesis. One important trend observed in the current study and other recent multicenter evaluations of

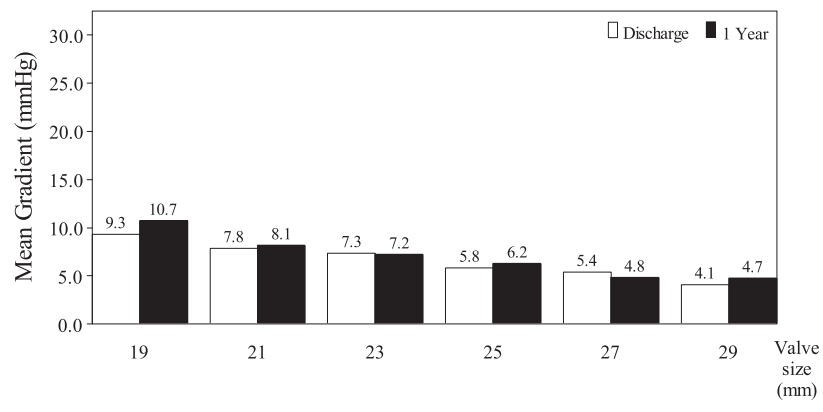

FIGURE 7. Average mean valve gradients over time. 


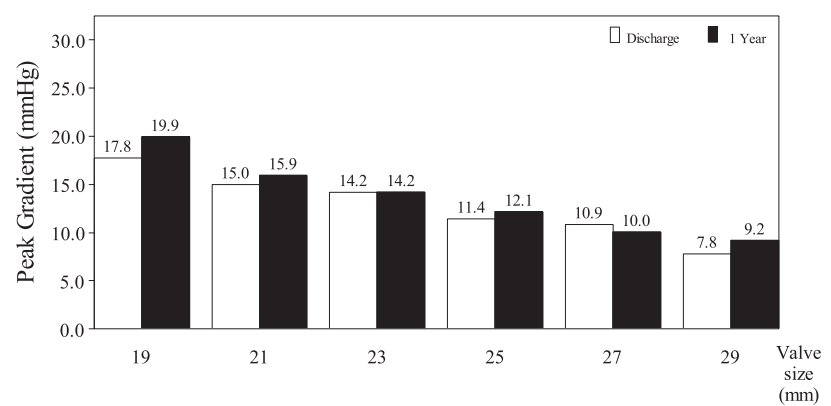

FIGURE 8. Average peak valve gradients over time.

biologic valve prostheses is that the average age of the patients was fairly high at 72.5 years. ${ }^{6,10,11}$ Despite the advanced age and higher risk profile, the clinical results of the patients in this study were exemplary. Perioperative mortality was $1.8 \%$, and overall survival was $94.5 \%$ at 2 years. This compares favorably to contemporary multicenter valve performance studies in similar patient populations by Conte and colleagues ${ }^{10}$ evaluating the Sorin Mitroflow (Sorin Group, Milan, Italy) pericardial aortic prosthesis, Fradet and colleagues ${ }^{11}$ evaluating the Medtronic Mosaic (Medtronic Inc, Minneapolis, Minn) porcine aortic prosthesis, and Jamieson and colleagues ${ }^{6}$ evaluating the St Jude Epic (St Jude Medical Inc) porcine prosthesis.

On the basis of the results of the current study, the Trifecta valve represents significant progress in the development of a stented bioprosthesis with near physiologic hemodynamics. The nearly cylindric opening of the prosthesis on systole provides gradients and EOAs that surpass any other available stented aortic prosthesis and approach those of stentless prostheses. $6,10-12,14,15$

Although study-to-study comparisons of different aortic prostheses are confounded by many factors, among multicenter studies with rigorous centralized core laboratory analysis echocardiographic follow-up, the Trifecta valve showed favorable hemodynamics to other pericardial prostheses. ${ }^{10,12}$ At 1 year, EOAs for the Trifecta valve, Sorin Mitroflow, ${ }^{10}$ Medtronic Mosaic, ${ }^{11}$ and Edwards Magna Ease ${ }^{12}$ (Edwards Lifesciences, Irvine, Calif) were $1.4,1.1,1.2$, and $1.3 \mathrm{~cm}^{2}$ for the $19-\mathrm{mm}$ prosthesis; $1.6,1.2,1.3$, and $1.5 \mathrm{~cm}^{2}$ for the

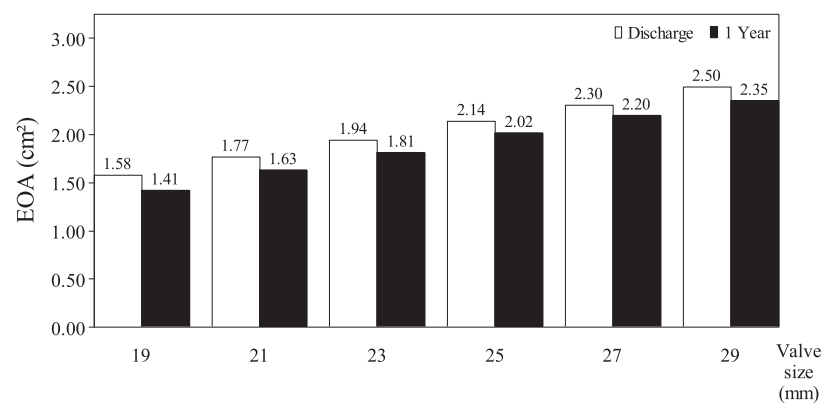

FIGURE 9. Average EOA. EOA, Effective orifice area.

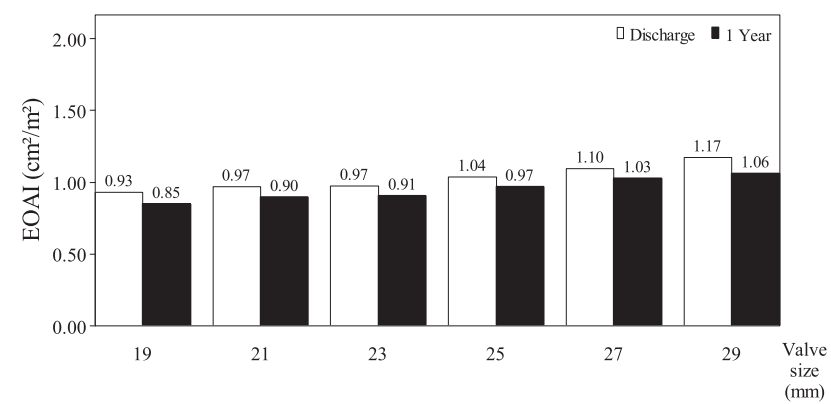

FIGURE 10. Average EOAI. EOAI, Effective orifice area index.

21-mm prosthesis; and $1.8,1.4,1.5$, and $1.8 \mathrm{~cm}^{2}$ for the 23-mm prosthesis, respectively. In a nominal size-by-size comparison, the 6-month EOAs for the Trifecta valve versus the St Jude Medical Toronto stentless porcine valve (full root implants only) were 1.7 and $1.2 \mathrm{~cm}^{2}$ for the $21-\mathrm{mm}$ prostheses, 1.9 and $1.5 \mathrm{~cm}^{2}$ for the 23-mm prostheses, 2.1 and 1.9 $\mathrm{cm}^{2}$ for the $25-\mathrm{mm}$ prostheses, 2.2 and $2.3 \mathrm{~cm}^{2}$ for the $27-\mathrm{mm}$ prostheses, and 2.5 and $2.6 \mathrm{~cm}^{2}$ for the $29-\mathrm{mm}$ prostheses, respectively. ${ }^{13}$ The presence of a titanium stent that may be able to expand during high loading conditions, such as exercise, may provide additional clinical benefit and minimize leaflet stresses as seen in stentless porcine valves. In addition, optimal leaflet shaping and coaptation are achieved through a proprietary leaflet fixation method.

The favorable hemodynamics led to an incidence of severe PPM that was uniquely low for the Trifecta valve. Among patients receiving 19-, 21-, and 23-mm prostheses, at 1 year, the mean EOAI was $0.85,0.90$, and $0.91 \mathrm{~cm}^{2} / \mathrm{m}^{2}$, respectively. Severe mismatch with an EOA less than 0.65 $\mathrm{cm}^{2} / \mathrm{m}^{2}$ was found in only $2.0 \%$ of patients at the time of discharge. The presence of severe PPM has been shown in several studies to lead to significantly poorer long-term survival in a variety of patient groups. In series with oldergeneration prostheses and varying definitions of mismatch, its incidence has been reported up to $51 \% .^{15,16}$

The discussion of near physiologic hemodynamics seen in the Trifecta valve is particularly important with the

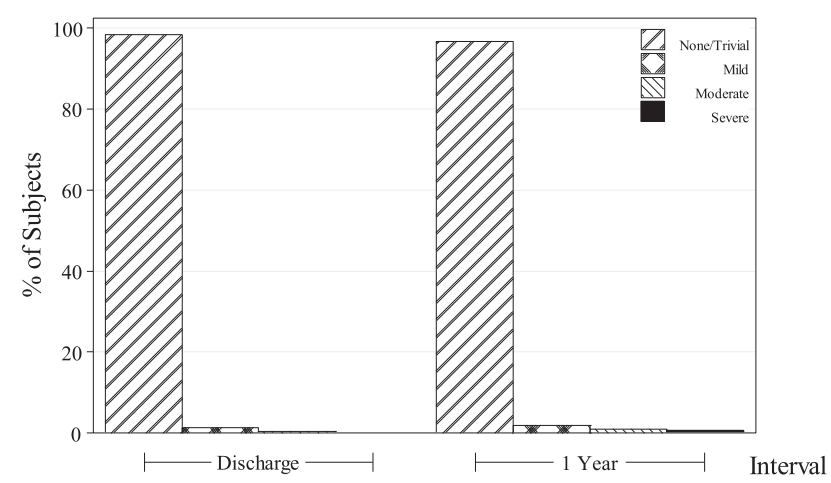

FIGURE 11. Total aortic insufficiency over time. 


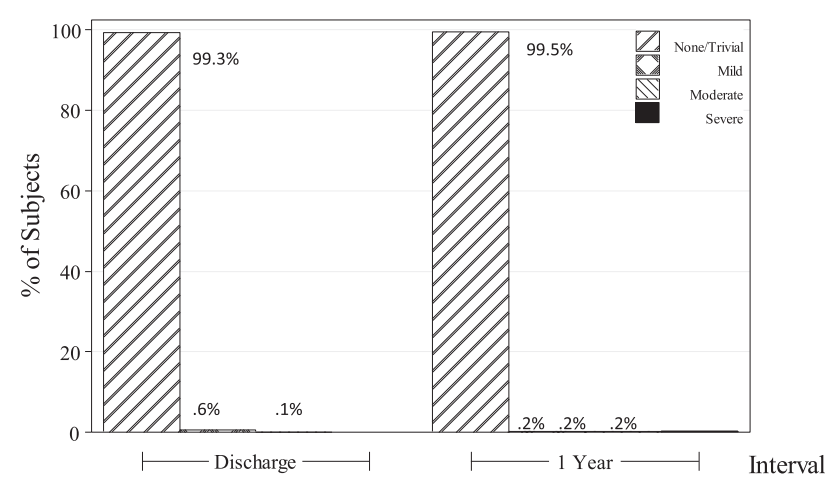

FIGURE 12. Paravalvular leak over time.

proliferation of transcatheter aortic valve replacement (TAVR) technologies. ${ }^{17-19}$ TAVR valves have been purported in several nonrandomized studies to have hemodynamics superior to open surgical valves, with low residual gradients due to the nonobstructive nature of the metallic stent and lack of sewing ring. ${ }^{19}$ In the only large multicenter randomized controlled trial comparing TAVR with open aortic valve replacement in high-risk patients, the difference in postoperative gradients was in the low single digits and not likely to be clinically significant. ${ }^{20}$ Although TAVR valves tend to be hemodynamically efficient in systole, paravalvular leaks, and to a lesser extent intravalvular leaks, seen frequently in the first-generation devices represent true sources of energy loss that may limit the full clinical benefit of the relief of severe aortic stenosis. A recent bench study by Azadani and colleagues ${ }^{21}$ revealed that energy loss in the setting of even mild aortic regurgitation from a paravalvular leak may be as hemodynamically important as a modest residual gradient. Aortic regurgitation, predominantly from paravalvular sources, is present in more than $51 \%$ of TAVR valves, and moderate or worse regurgitation is generally described in up to $13 \%$ of TAVR valves. ${ }^{17,18,22,23}$ In the current study, the Trifecta valve had a low rate of paravalvular leak (Figure 12) despite having a highly efficient low-profile sewing ring, indicative of ease of implantability. There was also minimal valvular

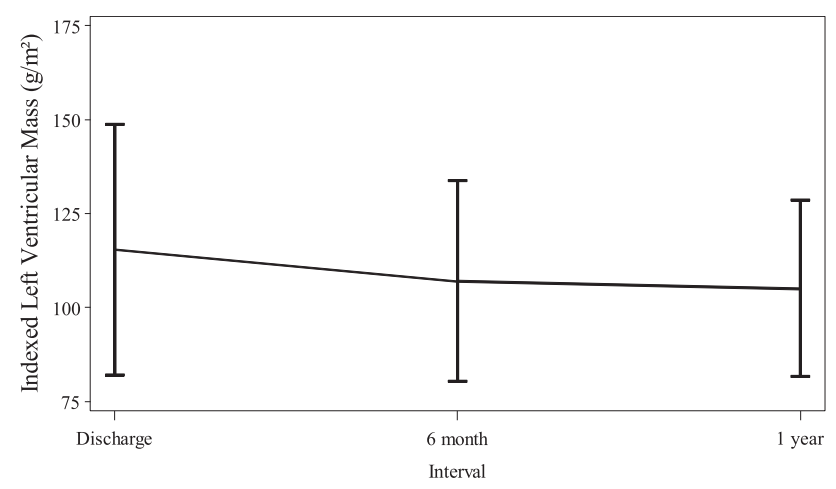

FIGURE 13. Left ventricular mass regression. regurgitation even in larger sizes, a problem more common in previous-generation surgical pericardial valves. ${ }^{24}$

\section{CONCLUSIONS}

The St Jude Medical Inc Trifecta valve is a unique pericardial bioprosthesis with design elements that incorporate significant improvements in hemodynamic performance over previous-generation valves while providing ease of implantation. Long-term follow-up continues to confirm the promising results of this innovative bioprosthesis.

\section{References}

1. Brown JM, O'Brien SM, Wu C, Sikora JA, Griffith BP, Gammie JS. Isolated aortic valve replacement in North America comprising 108,687 patients in 10 years: changes in risks, valve types, and outcomes in the Society of Thoracic Surgeons National Database. J Thorac Cardiovasc Surg. 2009;137:82-90.

2. Schoen FJ, Levy RJ. Founder's Award, 25th Annual Meeting of the Society for Biomaterials, perspectives. Providence, RI, April 28-May 2, 1999. Tissue heart valves: current challenges and future research perspectives. J Biomed Mater Res. 1999;47:439.

3. Flomenbaum MA, Schoen FJ. Effects of fixation back pressure and antimineralization treatment on the morphology of porcine aortic bioprosthetic valves. J Thorac Cardiovasc Surg. 1993;105:154.

4. Jones M, Eidbo EE, Hilbert SL, Ferrans VJ, Clark RE. Anticalcification treatments of bioprosthetic heart valves: in vivo studies in sheep. J Card Surg. 1989;4:69

5. Hilbert SL, Barrick MK, Ferrans VJ. Porcine aortic valve bioprostheses: a morphologic comparison of the effects of fixation pressure. J Biomed Mater Res. 1990;24:773.

6. Jamieson WR, Lewis CT, Sakwa MP, Cooley DA, Kshettry VR, Jones KW, et al. St Jude Medical Epic porcine bioprosthesis: results of the regulatory evaluation. J Thorac Cardiovasc Surg. 2011;141:1449-54.e2.

7. Edmunds LH Jr, Clark RE, Cohn LH, Grunkemeier GL, Miller DC, Weisel WD. Guidelines for reporting morbidity and mortality after valvular operations. Ad Hoc Liaison Committee for Standardizing Definitions of Prosthetic Heart Valve Morbidity of The American Association for Thoracic Surgery and the Society of Thoracic Surgeons. J Thorac Cardiovasc Surg. 1996;112:708-11.

8. Rahimtoola SH. Choice of prosthetic heart valve in adults: an update. J Am Coll Cardiol. 2010;55:2413-26.

9. Sharma S, Mehra A, Rahimtoola SH. Valvular heart disease: a century of progress. Am J Med. 2008;121:664-73.

10. Conte J, Weissman N, Dearani JA, Bavaria J, Heimansohn D, Dembitsky W, et al. A North American, prospective, multicenter assessment of the Mitroflow aortic pericardial prosthesis. Ann Thorac Surg. 2010;90:144-52,e1-3.

11. Fradet GJ, Bleese N, Burgess J, Cartier PC. Mosaic valve international clinical trial: early performance results. Ann Thorac Surg. 2001;71(5 Suppl):S273-7.

12. Edwards Life Sciences Corp. Carpentier-Edwards Magna Ease Pericardial Aortic Bioprosthesis Model 3300TFX Instructions for Use. Irvine, CA: Edwards Life Sciences Corp; 2009.

13. Gleason TG, David TE, Coselli JS, Hammon JW Jr, Bavaria JE. St. Jude Medical Toronto biologic aortic root prosthesis: early FDA phase II IDE study results. Ann Thorac Surg. 2004;78:786-93.

14. Lehmann S, Walther T, Kempfert J, Leontjev S, Rastan A, Falk V, et al. Stentless versus conventional xenograft aortic valve replacement: midterm results of a prospectively randomized trial. Ann Thorac Surg. 2007;84:467-72.

15. Moon MR, Pasque MK, Munfakh NA, Melby SJ, Lawton JS, Moazami N, et al. Prosthesis-patient mismatch after aortic valve replacement: impact of age and body size on late survival. Ann Thorac Surg. 2006;81:481-8.

16. Clavel MA, Webb J, Pibarot P, Altwegg L, Dumont E, Thompson C, et al. Comparison of the hemodynamic performance of percutaneous and surgical bioprostheses for the treatment of severe aortic stenosis. J Am Coll Cardiol. 2009;53: 1883-91.

17. Ewe SH, Muratori M, Delgado V, Pepi M, Tamborini G, Fusini L, et al. Hemodynamic and clinical impact of prosthesis-patient mismatch after transcatheter aortic valve implantation. J Am Coll Cardiol. 2011;58:1910-8.

18. Clavel MA, Webb JG, Rodés-Cabau J, Masson JB, Dumont E, De Larochellière R, et al. Comparison between transcatheter and surgical prosthetic 
valve implantation in patients with severe aortic stenosis and reduced left ventricular ejection fraction. Circulation. 2010;122:1928-36.

19. Zhao Y, Lindqvist P, Nilsson J, Holmgren A, Näslund U, Henein MY. Trans-catheter aortic valve implantation-early recovery of left and preservation of right ventricular function. Interact Cardiovasc Thorac Surg. 2011;12:35-9.

20. Smith CR, Leon MB, Mack MJ, Miller DC, Moses JW, Svensson LG, et al., PARTNER Trial Investigators. Transcatheter versus surgical aortic-valve replacement in high-risk patients. N Engl J Med. 2011;364:2187-98.

21. Azadani AN, Jaussaud N, Matthews PB, Ge L, Guy TS, Chuter TA, et al. Energy loss due to paravalvular leak with transcatheter aortic valve implantation. Ann Thorac Surg. 2009;88:1857-63.
22. Colli A, D'Amico R, Kempfert J, Borger MA, Mohr FW, Walther T. Transesophageal echocardiographic scoring for transcatheter aortic valve implantation: impact of aortic cusp calcification on postoperative aortic regurgitation. J Thorac Cardiovasc Surg. 2011;142:1229-35.

23. Moat NE, Ludman P, de Belder MA, Bridgewater B, Cunningham AD, Young CP, et al. Long-term outcomes after transcatheter aortic valve implantation in highrisk patients with severe aortic stenosis: the U.K. TAVI (United Kingdom Transcatheter Aortic Valve Implantation) Registry. J Am Coll Cardiol. 2011;58:2130-8

24. Vander Salm TJ, Toran AJ, Lewis W, O'Connor J. Severe, transient aortic insufficiency after bovine pericardial aortic valve replacement: a cautionary note. Ann Thorac Surg. 2009;88:672-4.

APPENDIX TABLE 1. Principal Investigator list

Principal Investigator

Joseph Bavaria, MD

Michael Petracek, MD

Hartzell Schaff, MD

Mark Groh, MD

Scott Goldman, MD

Kent Jones, MD

Vibhu Kshettry, MD

A. Marc Gillinov, MD

Marc Sakwa, MD

Mamdouh Bakhos, MD

David Kress, MD

Vaughn Starnes, MD

Joseph Coselli, MD

Donald Glower, MD

Stephen Dewan, MD

Thomas Kelly, MD

Charles Schwartz, MD

Allen Stewart, MD

Anson Cheung, MD

Eric Charbonneau, MD

Vivek Rao, MD

Jeremy Wood, MD

Guy Fradet, MD

Michel Pellerin, MD

Roderick MacArthur, MD

Frederick W. Mohr, MD, PhD

Frederik N. Hofman, MD

Alain Leguerrier, MD

Rüdiger S. Lange, MD, PhD

Thierry Carrel, MD, PhD

Gino Gerosa, MD, PhD
Investigational sites

Hospital of the University of

Pennsylvania

Vanderbilt Medical Center

Mayo Clinic

Mission Health and Hospitals

Lankenau Hospital

Intermountain Medical Center

Abbott Northwestern Hospital

Cleveland Clinic Foundation

William Beaumont Hospital

Loyola University Medical Center

St Luke's Medical Center

University of Southern California

St Luke's Episcopal Hospital

Duke University Medical Center

Cardiothoracic and Vascular Surgeons

Sarasota Medical Center

New York University Medical Center

Columbia University Medical Center

St Paul's Hospital

Hôpital Laval

Toronto General Hospital

Queen Elizabeth II Health Science Centre

Vancouver General Hospital

Institut de Cardiologie de Montréal

University of Alberta

Herzzentrum Leipzig GmbH

Onze Lieve Vrouw Gasthuis, Netherlands

CHRU Rennes

German Heart Center München

Inselspital Bern

Azienda Ospedaliera Di Padova 